\title{
Determination of Premature Birth Causes at Bint Al Huda Teaching Hospital
}

\author{
Adil Ali Hussein ${ }^{1}$, Asala Riyadh Mohammed ${ }^{2}$, Amer Muhasin Naser ${ }^{3}$ \\ ${ }^{1}$ Lecturer, College of Nursing, University of Basrah, ${ }^{2}$ Assistant Lecturer, College of Nursing, National University \\ for Science and Technology, ${ }^{3}$ Lecturer, Community Health Department, Nasiriyah Technical Institute, Southern \\ Technical University
}

\begin{abstract}
Objectives: The study aims to: To Determination Causes of Premature Birth at Bent-Al-Huda Teaching Hospital in Al Nasiriya City.

Methodology: Descriptive study design was conducted though out the present study for period from $6^{\text {th }}$ February 2020 to $1^{\text {st }}$ September 2020. A purposive (non- probability) sample of 100 patientsat Bent-AlHuda Teaching Hospital in Al Nasiriya City. Data were collected through the questionnaire constructed and the self-administrative reporting process. The questionnaire consisted of two parts: parents' sociodemographic variables (age, educational level, occupation, monthly income and residence).the second part consist of questionnaire consist of questions related to causes of premature birth. The validity of the content of the instrument was determined by a panel of experts, and the internal consistency of the instrument was determined through a pilot study and the calculation of the alpha correlation coefficient $(\mathrm{r}=0.870)$. Analyzing Data by descriptive and inferential statistical approaches using (SPSS) version 20.0.

Results: The findings shown that most of sample were fall in the age group 19-24 years old. The majority of premature birth gender are male, Level of education, the greater number of study sample do not read and write and they are accounted for (30\%) of the sample, the occupation status, the results showed that the highest percentages in the studied sample are (have no work), and are considered (70\%). Most of the monthly income of the study sample studied are insufficient and are considered (60\%). They majority of study sample were lives in rural area. The results of study show the highest percent of prevalence of these causes of premature birth among women which are (Malnutrition, Diseases in pregnancy, Early rupture of membranes, Repeated abortion and premature birth, early cervix Dilation and different blood type), there is statistically significant differences between causes of premature birth and (mother age, educational level and occupation) and there is non-statistically significant differences between causes of premature birth and (gender of premature birth, income and residence) at ( $\mathrm{p}$ value $>0.05$ ), when analyzed by Chi-Square Tests..
\end{abstract}

Recommendations: The study recommended to do Provide instructional heath education to pregnant women to increase their knowledge about causes of premature birth .

Keywords: Causes of Premature Birth, Pregnant women.

\section{Introduction}

If the baby is born before the 37 th week of pregnancy, it is called premature birth. Some preterm births happen on their own: the mother has contractions and the baby is born premature ${ }^{1}$. In other cases, pregnancy problems encourage doctors to give birth earlier than expected. About three-quarters of preterm births are spontaneous and about a quarter are due to medical complications. Overall, approximately one in eight pregnant women gives birth prematurely ${ }^{2}$. Preterm delivery is associated with $5-18 \%$ of pregnancies and is the leading cause of infant morbidity and mortality. Spontaneous premature birth, a syndrome caused by multiple pathological processes, leads to $70 \%$ of premature births. Prevention 
and treatment of premature birth are long-standing problems ${ }^{3}$. Summarize current understanding of disease mechanisms associated with this condition and review developments related to intraamniotic infection, decidual aging, and impaired maternal and fetal tolerance ${ }^{4}$.

The success of progesterone therapy in preventing preterm birth in a high-risk group of patients is cause for optimism. Unraveling the mystery of premature birth, which endangers the health of future generations, is a difficult and valuable scientific task ${ }^{5,6}$.

\section{Objectives of the study:}

1. To Determination Causes of premature birth at Bint Al Huda Teaching Hospital.

2. To find out association between causes of premature birth and socio-demographic variables of the study sample.

\section{Methodology}

In this chapter present the following:

Design of study: Descriptive study design was conducted though out the present study for period from $6^{\text {th }}$ February 2020 to $1^{\text {st }}$ September 2020.

The setting of the study: Study was conducted at Bint Al Huda Teaching Hospital in Al Nasiriya City.

Sample of the study: Randomize sampling of (100) patients that come and admitted to at Bint Al Huda Teaching Hospital in Al Nasiriya City.

\section{Criteria:}

A. Pregnant women at second and third trimester.

B. Patients accepted to cooperate in in study.

Tool of study: In order to determine the causes of premature birth the researchers constructed questionnaire consists of:

Part 1: Socio demographic characteristics includes (mother age, gender of child, educational level, occupation, monthly income, and residency).

Part 2: Questionnaire consist of questions related to causes of Premature Birth: includes (causes related mother, causes related uterus and placenta, and causes related fetus).

Ethical Considerations: Official permission was obtained from the administrative of Thi-Qar health office and from patients at Bint Al Huda teaching hospital before their inclusion in the study. The nature and aims of the study were explained to each of the participants.

Data collection: The data when collected with constructed questionnaire though an application direct interviewing and indirect answers as mean of data collection.

Statistical analysis: Data was analyzed using IBM. SPSS (version 20) to data was presented as number and percent data analyzed though an application of frequency and percent.

\section{Results}

Table (1): Distribution of the Study Sample According to the Demographical Variables

\begin{tabular}{|c|c|c|c|}
\hline Basic Information & Groups & Frequency & Percent \\
\hline \multirow{6}{*}{ Mother age } & $12-18$ & 25 & 25.0 \\
\hline & $19-24$ & 30 & 30.0 \\
\hline & $25-31$ & 25 & 25.0 \\
\hline & $32-38$ & 12 & 12.0 \\
\hline & 39 years and more & 8 & 8.0 \\
\hline & Total & 100 & 100 \\
\hline \multicolumn{4}{|l|}{ Mean \pm SD $23.2 \pm 1.083$} \\
\hline \multirow{3}{*}{ Gender of Premature Birth } & Male & 63 & 63.0 \\
\hline & Female & 37 & 37.0 \\
\hline & Total & 100 & 100 \\
\hline
\end{tabular}




\begin{tabular}{|c|c|c|c|}
\hline Basic Information & Groups & Frequency & Percent \\
\hline \multirow{7}{*}{ Education Level } & Not read and write & 15 & 15.0 \\
\hline & Read and write & 30 & 30.0 \\
\hline & Primary & 25 & 25.0 \\
\hline & Intermediate & 10 & 10.0 \\
\hline & Secondary & 18 & 18.0 \\
\hline & Institute and colleague graduation or higher & 2 & 2.0 \\
\hline & Total & 100 & 100 \\
\hline \multirow{3}{*}{ Occupation } & Have Work & 30 & 30.0 \\
\hline & Have no Work & 70 & 70.0 \\
\hline & Total & 100 & 100 \\
\hline \multirow{4}{*}{ Income } & Sufficient & 17 & 17.0 \\
\hline & Barely sufficient & 23 & 23.0 \\
\hline & Insufficient & 60 & 60.0 \\
\hline & Total & 100 & 100 \\
\hline \multirow{3}{*}{ Residency } & Urban & 57 & 57.0 \\
\hline & Rural & 43 & 43.0 \\
\hline & Total & 100 & 100 \\
\hline
\end{tabular}

$\mathrm{F}=$ Frequency, $\%=$ Percent

This table shows that (30\%) of pregnant women are in the age group (19-24) years, with mean (23.2) years. Concerning the gender of preterm birth, the largest number of study sample are male $(63.0 \%)$, and the level of education, were largest number of them read and write and constituted (30\%) of the sample.
Regarding the occupation, the results showed that a higher percentage of the studied sample is (have no work) $(70 \%)$ of the study sample. The majority of monthly income of the study sample individuals are insufficient $(60 \%)$, and the residency are most of the study sample live in the urban area (57\%).

Table (2) Statistics of Study Sample Regarding Causes of Premature Birth

\begin{tabular}{|c|c|c|c|c|c|}
\hline \multirow{2}{*}{ No } & \multirow{2}{*}{ Items } & \multicolumn{2}{|c|}{ Yes } & \multicolumn{2}{|c|}{ No } \\
\hline & & $\mathbf{F}$ & $\%$ & $\mathbf{F}$ & $\%$ \\
\hline \multirow{6}{*}{1} & \multicolumn{5}{|l|}{ Causes Related to Mother } \\
\hline & Malnutrition. & 62 & 62.0 & 38 & 38.0 \\
\hline & Diseases in pregnancy. & 88 & 88.0 & 22 & 22.0 \\
\hline & Early rupture of membranes. & 55 & 55.0 & 45 & 45.0 \\
\hline & $\begin{array}{l}\text { Chronic diseases of the mother such as blood pressure, heart disease and kidney } \\
\text { disease }\end{array}$ & 44 & 44.0 & 56 & 56.0 \\
\hline & Chronic anemia & 25 & 25.0 & 75 & 75.0 \\
\hline \multirow{5}{*}{2} & Causes Related Uterus and Placenta & & & & \\
\hline & Repeated abortion and premature birth. & 65 & 65.0 & 35 & 35.0 \\
\hline & Early cervix dlation. & 77 & 77.0 & 23 & 23.0 \\
\hline & Tumors & 10 & 10.0 & 90 & 90.0 \\
\hline & Placental detachment. & 20 & 20.0 & 80 & 80.0 \\
\hline
\end{tabular}




\begin{tabular}{|c|l|c|c|c|c|c|}
\hline \multirow{2}{*}{ No } & \multirow{2}{*}{ Items } & \multicolumn{4}{|c|}{ Yes } & \multicolumn{3}{|c|}{ No } \\
\cline { 2 - 7 } & & F & \% & \multicolumn{5}{|c|}{ F } & \% \\
\hline \multirow{3}{*}{3} & Causes Related Fetus & \multicolumn{5}{|c|}{} \\
\cline { 2 - 7 } & Multiple pregnancy. & Congenital defects. & 23 & 23.0 & 77 & 77.0 \\
\cline { 2 - 7 } & Radiation & 19 & 19.0 & 81.0 & 81.0 \\
\cline { 2 - 7 } & Different blood type & 0 & 0.00 & 100 & 100.0 \\
\hline
\end{tabular}

$\mathrm{f}=$ frequency, $\%=$ percent

This table shows the distribution the causes of premature birth this show the major causes of premature birth (Malnutrition, Diseases in pregnancy, Early rupture of membranes, Repeated abortion and premature birth,early cervix Dilation anddifferent blood type).

Table (3): Association of Causes of Premature Birth and Socio-demographic Variables of Study Sample

\begin{tabular}{|c|c|c|c|c|c|c|}
\hline \multirow{2}{*}{$\begin{array}{ll}\text { Variables } & \text { Socio-demographic } \\
\end{array}$} & \multicolumn{6}{|c|}{ Statistics } \\
\hline & $\mathbf{N}$ & Mean \pm S.D. & $\chi^{2}$ & d.f & P. value & Sig \\
\hline Mother age & 100 & $2.41 \pm 1.083$ & 279.911 & 99 & 0.016 & $\mathrm{~S}$ \\
\hline Gender of Premature Birth & 100 & $1.37 \pm 0.485$ & 97.140 & 99 & 0.113 & NS \\
\hline Education Level of Mother & 100 & $2.28 \pm 0.996$ & 199.700 & 99 & 0.014 & $\mathrm{~S}$ \\
\hline Occupation & 100 & $1.61 \pm 0.751$ & 33.165 & 99 & 0.031 & S \\
\hline Income & 100 & $1.86 \pm 0.349$ & 142.759 & 99 & 0.947 & NS \\
\hline Residence & 100 & $1.53 \pm 0.502$ & 48.390 & 99 & 0.34 & NS \\
\hline
\end{tabular}

This table show there is statistically significant association between causes of premature birth and (mother age, educational level of mother and occupation) and there is non-statistically significant differences between causes of premature birth and (gender of premature birth, income and residence) at ( $p$ value $>$ 0.05), when analyzed by Chi-Square Tests.

\section{Discussion}

Part-I: Discussion Association between Causes of Premature Birth and Socio-Demographic Variables of the Study Sample: Related to determination causes of premature birth in Bint Al Huda Teaching hospital in Al Nasiriya city. The results of the study show that most of the study sample occurrence of these causes which is (Malnutrition, Diseases in pregnancy, Early rupture of membranes, Repeated abortion and premature birth,early cervix Dilation and different blood type), this results agree with study done by Goldenberg et $\mathrm{al}^{7}$ that group of factors that contribute to causes premature birth such as nutrition, some diseases during pregnancy, premature rupture of membrane, and previous cases of preterm baby. These finding support and agree present study.

Part-II: Association of Causes of Premature Birth and Socio-demographic Variables of Study Sample: The present study findings shows statistically significant association between causes of premature birth and mother age these results supported by Schleußner ${ }^{8}$, that said the maternal age is the ones of causes of premature birth. Regarding the gender of premature birth Di Renzo et $\mathrm{al}^{9}$ that concluded male gender is an independent risk factor for negative pregnancy outcomes. Evidence suggests that female have an advantage over male with better perinatal outcomes, especially after preterm labor, these finding result not compatible with present finding that funded there is no association between gender of premature birth with labor. Regarding mother level of education with premature birth, result of the present study accompanied with result funded by Shah et $\mathrm{al}^{10}$ significant association between mother education and incidence of premature birth. Klerman et $\mathrm{al}^{11}$ disagree 
with present study findings due to who funded there is relationships between residence and family income with premature birth.

\section{Conclusion}

1. A highest percent of the study sample were male gender premature more than females, they women with low level of education were read and write, and primary school and married. They were no have work, having insufficient monthly income.

2. The determination causes of premature birth are (Malnutrition, Diseases in pregnancy, Early rupture of membranes, Repeated abortion and premature birth, early cervix Dilation and different blood type).

\section{Recommendations:}

1. Extensive and comprehensive population-level (national) studies can be carried out to determine the causes of preterm birth.

2. Provide instructional heath education to pregnant women to increase their knowledge about causes of premature birth.

Financial Disclosure: There is no financial disclosure.

Conflict of Interest: None to declare.

Ethical Clearance: All experimental protocols were approved under the University of Basrahand all experiments were carried out in accordance with approved guidelines.

\section{References}

1. Spinelli M, Frigerio A, Montali L. 'I still have difficulties feeling like a mother': The transition to motherhood of preterm infants mothers. Psychology \& health. 2016; 31(2): 184-204.
2. Davis D. Reproductive Injustice: Racism, Pregnancy, and Premature Birth. NYU Press. 2019; 7.

3. Borders N. After the afterbirth: a critical review of postpartum health relative to method of delivery. Journal of midwifery \& women's health. 2006; 51(4): 242-248.

4. Nadeau-Vallée M, Obari D, Palacios J. Sterile inflammation and pregnancy complications: a review. Reproduction. 2016; 152(6): R277-R292.

5. Romero R, Dey SK, Fisher SJ. Preterm labor: one syndrome, many causes. Science. 2014; 345(6198): 760-765.

6. Abubakar I, Tillmann T, Banerjee A. Global, regional, and national age-sex specific all-cause and cause-specific mortality for 240 causes of death, 1990-2013: a systematic analysis for the Global Burden of Disease Study 2013. Lancet. 2015; 385(9963): 117-171.

7. Goldenberg R, Culhane J. Epidemiology and causes of preterm birth. The lancet. 2008; 371(9606): 7584.

8. Schleußner E. The prevention, diagnosis and treatment of premature labor. Deutsches Arzteblatt international. 2013; 110(13): 227-236.

9. Di RenzoG, Rosati A, Sarti R. Does fetal sex affect pregnancy outcome?. Gender medicine. 2007; 4(1): 19-30.

10. Shah $\mathrm{P}$, Balkhair $\mathrm{T}$, Ohlsson, $\mathrm{A}$. Intention to become pregnant and low birth weight and preterm birth: a systematic review. Maternal and child health journal. 2011; 15(2): 205-216.

11. Klerman LV, Cliver SP, Goldenberg RL. The impact of short interpregnancy intervals on pregnancy outcomes in a low-income population. American Journal of Public Health. 1998; 88(8): 1182-1185. 